\title{
Improving Service Effectiveness in the High-Class Hotels in Varna (Bulgaria)
}

\author{
Georgina Lukanova ${ }^{1}$
}

Received: 14/01/2013

\begin{abstract}
${ }^{1}$ Department of Economics and the Organization of Tourism, University of Economics Varna, 77 Kniaz Boris I. Blvd., 9002 Varna, Bulgaria; tel: +359 52660 434; e-mail: lukanova@ue-varna.bg
\end{abstract}

Supervisor: Assoc. Prof. Tanya Dabeva, PhD

Institution awarding the Ph. D. Degree: University of Economics-Varna, Bulgaria Date of defence: $19^{\text {th }}$ October 2012

(C) 2013 International University College. All rights reserved

Citation: Lukanova, G. (2013). Improving service effectiveness in the high-class hotels in Varna (Bulgaria). Doctoral dissertation summary. European Journal of Tourism Research 6(1), 88-91.

\section{Goal and objectives of the dissertation Goal}

To provide theoretical foundations and carry out empirical research on service in high-class hotels in Varna, in order to identify key opportunities for improving its effectiveness.

\section{Objectives}

$\checkmark$ To define the delivery of hotel service

$\checkmark$ To analyse its specific characteristics and mechanisms

$\checkmark$ To define the effectiveness of the service delivery system

$\checkmark$ To develop a conceptual model and methodology for evaluating the effectiveness of the hotel service delivery system

$\checkmark$ To investigate consumer satisfaction with service in the high-class hotels in Varna

$\checkmark$ To investigate the managers' assessment of service delivery systems in high-class hotels in Varna

$\checkmark$ To identify issues and proposals to improve service effectiveness in the city's high-class hotels

88

\section{Methodology}

This dissertation employs a variety of research methods: analysis and synthesis; observation, survey questionnaire and in-depth interview; comparative analysis; and descriptive, statistical and mathematical methods. Empirical data have been collected through the questionnaire surveys, and the relevant responses have been processed using SPSS software. The purpose of the questionnaire survey method is to evaluate the service delivery system from both the customer' and the managers' point of view.

Service effectiveness in the hotel sector is assessed via a concept model, based on the systems approach. Hotel service is represented as a system with input values, procedures and final results. The assessment of service effectiveness is made through a selection of criteria, taking into consideration the special features of hotel operations, as well as the providers and recipients of the service operation. There is a double assessment of benefits and DOCTORAL DISSERTATION 
Lukanova, G. (2013) / European Journal of Tourism Research 6(1), 88-91.

effects - both for the hotel organization and for its customers.

\section{Results}

The situational analysis of the city's hotel sector shows a steady downward trend in the number of hotels in Varna municipality due to oversaturation; there is also a decrease in the relative role of hotels in the accommodation structure of the municipality. Nevertheless, hotels provide the largest percentage of the total accommodation capacity (number of beds) and they are the preferred accommodation establishments on the territory of the municipality, with three- and four-star hotels having the largest market share. Small and medium-sized independent hotels predominate and only two international chains have properties in Varna.

The analysis of high-class hotels in Varna shows that all 16 hotels from the surveyed group have a central or near central location; the hotel room rates are generally directly proportional to their star rating; in terms of the type structure, the hotels in the target group fall into three groups: 1 . boutique hotels; 2 . business hotels; 3 . classic town hotels.

Based on the results of the managers' survey, we can make the following conclusions:

$\checkmark$ Hotel managers value quite highly the role of the internet as a source of information, as an opportunity for advertising and as a convenience for potential customers;

$\checkmark$ Hotel service in welcoming and checking in the guest is effective and its strengths are associated with the personal qualities of service employees and the physical environment;

$\checkmark$ Hotel management considers as most important guests' first and last contact with the hotel, and therefore, it is the operations at those two times that are given the greatest weight in the assessments.

Weaknesses occur in the following areas and it is these areas that offer opportunities for development in the future:

$\checkmark$ Lack of a clear and precise understanding on the part of management of all the opportunities that are available; $\checkmark$ Ability of hotel staff to sell available services;

$\checkmark$ Checking guests into their rooms;

$\checkmark$ Quality of the physical environment;

$\checkmark$ Maintaining ongoing relationships with the guests

The main conclusions from the customers' satisfaction and assessment survey are as follows:

$\checkmark$ Most reliable information source, according to tourists, is word of mouth from friends and acquaintances, as well as reviews by other tourists found on social network sites and internet forums. This forces managers to focus their attention and efforts on the image of the hotel.

$\checkmark$ Most potential customers prefer to book a hotel service online; hence the need to design online hotel reservation systems intended for end users, and to ensure visibility on the most popular sites used for hotel reservations.

$\checkmark$ On the whole, the tourists surveyed assess front office service as effective. The employees' personal qualities get high marks.

$\checkmark$ In regard to the physical environment, high marks are given for those material elements that are the most important for guest satisfaction.

$\checkmark$ The majority of tourists consider the service/price correlation to be fair, which means that potential customers would tolerate a price increase as long as it involves improvements of service.

$\checkmark$ The image of high-class hotels is good, taking into consideration that most of the tourists are determined to come back for another visit and to give the hotel good reviews.

$\checkmark$ The problems that stand out are mostly connected with the technical side of service, the qualitative characteristics of the material environment, the variety and quality of additional services and the customer/employee relations.

On the basis of our analysis we can assert that, on the whole, service effectiveness was rated either very good or excellent, both from the point of view of supply and demand. This observation is supported by the t-test on the differences between the responses of hotel 
Improving service effectiveness in the high-class hotels in Varna (Bulgaria). Doctoral dissertation summary.

managers and customers. Results show that there are almost no statistically significant differences between managers' and customers' assessments. The conclusion is reached that high-class hotels in Varna manage to satisfy the demands of the users, offering guests all the desired components of hotel service.

\section{Theoretical conclusions}

In recent decades there has been a growing interest in hotel service, in strategies for its improvement and in understanding how customers perceive it. Modern hotel industry development involves competition not so much in terms of what is offered, inasmuch as in most cases the services and goods offered are similar throughout a given hotel category, as in terms of how it is offered. This forces the hotel organizations to focus on effective service systems, on creating customer values and on the long-term success of the organization.

Hotel service can be defined as a system intended for the delivery of hotel services in which people, materiel and information are organized and operated in a certain way, so as to create customer value and benefits for the hotel organization. The components mentioned above operate and come together in time and space in a certain way, which is unique at any given time. That is, there occurs a process of providing and using services that leads to a specific result. For the customer the end result is commensurate with non-material values of a social and psychological nature. For the hotel organization the end results can be both economic and non-economic. The former include sales growth, rising income and profit, increased occupancy of hotel rooms, increased market share, etc. The latter include improved image, higher brand consciousness among users, growth in numbers of satisfied customers, creation of loyal customers, attracting new customers, etc. In the hotel industry, viewed as a hospitality industry, the benefits for the hotel organization are the direct consequence of benefits for the customers.

Effectiveness is a characteristic feature of the system of service in the hotel industry, which reflects above all the level reached in achieving the aims of the hotel organization. Defining the process as effective or ineffective is connected not only with its preparation, but also with the needs that are met. In this sense it may be asserted that service effectiveness in the hotel sector is connected with the purposefulness of the operations. This implies that in assessing effectiveness one must take into account the purpose of the service system as well as the results produced by the action of the system. It has been pointed out that the basic purpose of a hotel service system is to create value for the customer and benefit for the organization. As a result, in order for a hotel service system to be effective, it must assure the use of correct operations in providing quality customer service and thus meet their needs and provide benefits for the hotel organization.

\section{Practical application of the dissertation}

In order to raise service effectiveness, it is important for hotel organizations to anticipate and exceed guest expectations. To achieve successful development, every hotel organization must show that it is capable of discovering and introducing new and unique elements in its service system, which not only satisfy the customers but will actually charm and delight them. There is no universal prescription, but we believe that the fundamental strategic directions for achieving a higher level of service effectiveness in the highclass hotel sector can be sought in the following:

$\checkmark$ Improved operations. There are two applicable approaches: standardization and personalization, which can be combined into a single common strategy for raising the effectiveness of hotel service both for hotel organizations and for their customers.

$\checkmark$ Introduction of innovations: in the current strongly competitive environment innovation may be regarded as one of the most important components of the corporate strategies of hotel organizations inasmuch as it ensures a competitive advantage and raises the effectiveness of each component of the service system.

$\checkmark$ Use of modern information and communication technology: modern hotel business development makes them an inseparable part of the management and 
operations of a hotel and they are applied at each level of the hotel service. The introduction of modern IT in hotel service leads to the improvement of communication with current and potential guests based on a timely and adequate response to market changes. Experience shows that those hotels that use effective technologies adequately have greater short-and long-term success.

$\checkmark$ Managing customer relations: the goal of a customer relations management strategy is to minimize expenses and to maximize the profitability of the firm, by means of increasing the customers' level of satisfaction and the creation of loyal customers. This management approach is based on the whole hotel organization being engaged in identifying each individual customer and building strong relations, which are to be maintained, until they are mutually beneficial. In this way, the management of customer relations can produce the final goal of the service system: creation of customer value and benefits for the hotel organization.

In conclusion, the necessary condition for longterm success in hotel organizations, in a climate of growing supply, increasing competition, as well as the rise of more experienced and better informed customers, is the readiness of an organization for flexible management thinking, for change and for adaptation. The recommendations made are not peremptory, rather the choice of possibilities depends on the ability of the hotel organizations to create and support an excellent material environment, competent staff and an evolved management philosophy.

\section{Content of the dissertation}

\section{Abstract of chapter one}

The first chapter of the dissertation provides a theoretical basis for service in the hotel sector, compares the different definitions of the service concept offered by different authors and schools of thought, and identifies its essential characteristics. Special attention is devoted to the role of the human resources (both the customers and the hotel staff who come into direct contact with them). The special features of hotel service effectiveness are revealed and effectiveness is compared to other concepts, such as efficiency and productivity. A concept model is suggested for the assessment of hotel service effectiveness, on the basis of the system approach. The assessment of service effectiveness is made by means of selecting criteria consistent with the special features of hotel operations.

\section{Abstract of chapter two}

The analysis and assessment of service in high-class hotels are presented as a specific research process. The situational analysis covers the years 2000-2011. We study quantitative, qualitative, and structural indicators, such as the dynamics of accommodation in Varna municipality, type structure, capacity distribution regarding different types of accommodation, hotel category structure etc. Different aspects of service regulation are studied in the surveyed hotels. Problems are defined and an assessment of service effectiveness in highclass hotels in Varna is made from two viewpoints: hotel supply and hotel demand. In order to reach adequate conclusions we have performed a comparative assessment of the average values of customers' and managers' responses, revealing statistically significant differences between the two groups.

\section{Abstract of chapter three}

The above analysis of the actual service effectiveness achieved in the high-class hotels in Varna serves as the basis for outlining the fundamental possibilities for improvement. These are divided into the following main sectors: the introduction and development of innovations in the hotel industry; the use of modern information and communications technology; the application of new business strategies for managing customer relations. The recommendations offered in chapter three of the dissertation for improving the effectiveness of hotel service are of several fundamentally different types. In part they are based on the good practices of renowned hotels with an international reputation. Some could be applied directly in Bulgarian hotels, while others could serve as the basis for generating innovative ideas. 